\title{
Male territorial aggression and fitness in collared flycatchers: a long-term study
}

\author{
Eszter Szász ${ }^{1}$ (D) Mónika Jablonszky ${ }^{1} \cdot$ Katalin Krenhardt $^{1} \cdot$ Gábor Markó $^{1,2} \cdot$ Gergely Hegyi $^{1}$ - Márton Herényi ${ }^{1,3}$. \\ Miklós Laczi ${ }^{1,4}$. Gergely Nagy ${ }^{1}$ • Balázs Rosivall ${ }^{1}$ • Eszter Szöllösi ${ }^{1}$ • János Török ${ }^{1,5}$ • László Zsolt Garamszegi ${ }^{6,7}$
}

Received: 3 May 2018 / Revised: 14 December 2018 / Accepted: 5 February 2019 /Published online: 8 March 2019

(C) The Author(s) 2019

\begin{abstract}
Aggressive behaviour plays a fundamental role in the distribution of limiting resources. Thereby, it is expected to have consequences for fitness. Here, we explored the relationship between aggression and fitness in a long-term database collected in a wild population of the collared flycatcher (Ficedula albicollis). We quantified the aggression of males during nest-site defence by conducting simulated territorial intrusions in the courtship period. We estimated the fitness of males based on their pairing success, breeding output and survival to next year. Earlier arriving and older males had a higher probability to establish pairbond, and males that started to breed earlier fledged more young. Aggression did not predict pairing and breeding performances. However, the probability of a male to return in the next year was significantly related to aggression in an age-dependent manner. Among subadult males, more aggressive individuals had higher chances to return, while among adult males, less aggressive ones did so. This finding is in harmony with our general observation that subadult collared flycatcher males behave more aggressively than adult males when confronted with a conspecific intruder. Subadult males may be socially inexperienced, so they should be more aggressive to be successful. In contrast, if adult males suffer from higher physiological costs, a lower level of aggression may be more advantageous for them. Our study shows that aggressive behaviour can be a fitness-related trait, and to understand its role in determining fitness, age should be taken into account.
\end{abstract}

Keywords Life-history $\cdot$ Male-male contest $\cdot$ Passerine $\cdot$ Personality $\cdot$ Territorial competition

\section{Introduction}

Behaviours that are directed toward conspecifics involving elements that can intimidate or harm the opponent and are performed with the goal of ensuring the access and

Communicated by: Pamela Cecile Rasmussen

Electronic supplementary material The online version of this article (https://doi.org/10.1007/s00114-019-1606-0) contains supplementary material, which is available to authorized users.

Eszter Szász

iciperezvon@gmail.com

1 Behavioural Ecology Group, Department of Systematic Zoology and Ecology, Eötvös Loránd University, Pázmány Péter sétány 1/C, Budapest 1117, Hungary

2 Department of Plant Pathology, Szent István University, Villányi út 29-43, Budapest 1118, Hungary

3 Department of Zoology and Animal Ecology, Szent István University, Páter Károly utca 1, Gödöllö 2100, Hungary maintenance of limited resources (such as space, sexual partner and food) are called aggression (Maynard Smith et al. 1988). In the case of territorial aggression, the stake is a monopolisable area, which should be defended from samesex and advertised to opposite-sex individuals. Aggression is

\section{Hungary}

5 Ecology Research Group of the Hungarian Academy of Sciences, Pázmány Péter sétány 1/C, Budapest 1117, Hungary

6 Departamento de Ecología Evolutiva, Estación Biológica de Donaña-CSIC, C/Americo Vespucio, 26, 41092 Seville, Spain

7 MTA-ELTE Theoretical Biology and Evolutionary Ecology Research Group, Department of Plant Systematics, Ecology and Theoretical Biology, Eötvös Loránd University, Pázmány Péter sétány $1 / C$, Budapest 1117 , Hungary 
one of the most widespread behavioural traits in the animal kingdom. In many songbird species that defend breeding or foraging sites, aggression has been found to be an individualspecific trait, repeatable within individuals during a single or over multiple breeding seasons (collared flycatcher (Ficedula albicollis), Garamszegi et al. 2006; dark-eyed junco (Junco hyemalis), Cain et al. 2011, Cain and Ketterson 2012; eastern bluebird (Sialia sialis), Burtka and Grindstaff 2013, Harris and Siefferman 2014; tree swallow (Tachycineta bicolor), Rosvall 2008, Betini and Norris 2012; western bluebird (Sialia mexicana), Duckworth 2006; wood warbler (Phylloscopus sibilatrix), Szymkowiak and Kuczyński 2017). Because of its fundamental role in sexual selection, aggression is a particularly relevant behavioural trait for fitness and has either direct or indirect consequences for both reproductive success and survival of the individuals. Furthermore, the pace-of-life syndrome hypothesis explicitly proposes that individual-specific behaviours are parts of the fast-slow life-history (or life-style, if we are speaking of within-population patterns) continuum (Réale et al. 2010). If so, patterns of balancing the investment in current reproductive success and future survival may correlate with the expression of aggression.

Aggression could influence reproductive success in several ways. First, aggression may determine settlement patterns at the beginning of the breeding season. Accordingly, more aggressive males would occupy territories faster and of higher quality (Fretwell and Calver 1970; Robinson and Terborgh 1995; Duckworth 2006; Rosvall 2008, 2011; Scales et al. 2013), and they defend it more efficiently from rival males (Yasukawa 1979). The timing of breeding and nest-site quality are known to have crucial importance to reproductive success, especially in seasonally breeding species (Bensch and Hasselquist 1991; Ens et al. 1992; Verhulst et al. 1995). Furthermore, females, when considering potential mates, can also decide based on territory quality (Alatalo et al. 1984, 1986). Second, aggression may be a determinant of pairing success as well. Females can rely on traits displayed during territorial aggression by eavesdropping on male-male confrontations and either prefer or avoid more aggressive males (Otter et al. 1999; Ophir and Galef 2003; Ophir et al. 2005; Kunc et al. 2006). From this action, females could benefit if aggression signals the quality of the territory or that of the individual (Berglund et al. 1996) or future parental care (Candolin 2000). It is also possible that aggression is linked to behaviours that are used specifically to attract females (such as singing and displaying; Garamszegi et al. 2008), by which aggression is indirectly involved in mate choice. Third, aggression may influence paternity gain and loss if it is coupled with ejaculate quality (Rojas Mora et al. 2017), mate guarding and/or copulation frequency (Ophir et al. 2005) and/or extrapair activity (Spoon et al. 2007; van Oers et al. 2008). Lastly, aggression may influence hatching and fledging success either via nest-site quality (see above), differential maternal allocation (Grenna et al. 2014; Szász et al. 2014) or paternal provisioning, which can be negatively related to aggression (Duckworth 2006; Mutzel et al. 2013).

Aggression may be advantageous for some aspects of reproductive success, while disadvantageous for other aspects (even for the same aspect, its pay-off may be context-dependent). Consequently, there is potential for several trade-offs regarding the link between aggression and reproductive success. In the courtship period, males have to balance their time and energy investment between mate attraction and male-male competition. If males differ in their level of aggression because they follow different allocation strategies to resolve this trade-off, more aggressive and less aggressive males may eventually realise similar reproductive success. A similar decisional conflict could arise in the parenting period, if the consequences of aggression are positive on nest defence while negative on incubation or provisioning (Duckworth 2006, Mutzel et al. 2013).

Aggression could also have consequences for fitness beyond the current breeding event. It could relate to survival directly because of the risk of getting injured and exposed to parasite infections as emerging from the physical confrontations during territorial fights (Hof and Hazlet 2012). Furthermore, aggression could influence survival indirectly in multiple ways. First, it may have physiological costs if the high testosterone levels that promote aggression interfere with immune responses (Folstad and Karter 1992; Sheldon and Verhulst 1996). Second, if aggression enhances the acquisition of territory and/or food of superior quality and/or quantity, these will translate to higher survival prospects. Third, aggression may be linked to other behaviours or other phenotypic traits that have an effect on survival. For example, aggression may correlate with exploration (Verbeek et al. 1996), and exploration may also correlate with parasite load (Dunn et al. 2011). Risk-taking, which can also form a behavioural syndrome with aggression (Garamszegi et al. 2015), may confer a higher probability of being depredated (Sih et al. 2004).

There is a potential, overall trade-off regarding what level of aggression pays off advantageously in terms of fitness. This is because the same level of aggression may increase reproductive success, but at the same time, may decrease survival chance, or vice versa. The solution to that conflict may depend on the relative value of current and future reproduction for each individual (Williams 1966). In such a case, because current aggression is adjusted to future prospects at the individual level, we may find similar long-term or lifetime fitness of more aggressive and less aggressive males, as long as the variation in overall budget or quality (for example body size or lifespan) among individuals is not large. This concept also suggests that short-term, such as seasonal, fitness pay-offs from aggression may change during the lifetime of the individual. For example, individuals may behave differently as 
they age. Alternatively, trade-offs could be diminished by a considerable among-individual variation in overall budget or quality (van Noordwijk and de Jong 1986). Accordingly, individuals with higher investment capacity or of better quality could afford to be more aggressive, and at the same time, reproduce more successfully and survive better.

In the present study, given that several hypotheses predict relationship between aggression, reproductive success and survival, we aimed to disentangle the fitness correlates of nest-site defence aggression in an exceptionally long-term database collected in a wild population of collared flycatchers. For over a decade now, we have been assaying male aggression behaviour during courtship, in a standardised way. An earlier study in our study population showed that within a breeding season, males express aggression in an individualspecific way as male identity significantly explained variation in propensity to attack (Garamszegi et al. 2006). Accordingly, aggression of the same individual was found to be repeatable during a single breeding season (Garamszegi et al. 2012, 2015). However, it was non-repeatable over multiple seasons (Garamszegi et al. 2015). Aggression was also age-dependent as subadults showed considerably stronger responses toward intruders than adults (Garamszegi et al. 2006). Furthermore, aggression seems to be part of a behavioural syndrome as it was significantly and positively correlated with risk-taking across individuals over multiple study years (Garamszegi et al. 2015). Our earlier results also indicated that aggression level of males may play a role in sexual selection and sex allocation, because it predicted how fast they subsequently established a pair-bond (Garamszegi et al. 2006) and what proportion of sons they had in their brood (Szász et al. 2014). However, other proxies of fitness have not been considered earlier; thus, it remains to be identified how reproductive output and survival of males relate to their aggression during nest-site defence. Given that both the underlying theory and the available empirical results vary in the direction of relationship between aggression and fitness traits, we could not formulate specific predictions concerning the sign of the focal correlations in our study population.

\section{Methods}

\section{Study species and study area}

The study was conducted in a nest-box breeding population of the collared flycatcher in the Pilis-Visegrádi Mountains, Hungary $\left(47^{\circ} 43^{\prime} \mathrm{N}, 19^{\circ} 01^{\prime} \mathrm{E}\right)$. The study plots are situated in a protected, middle-aged, oak-dominated forest in the Duna-Ipoly National Park and consist of ca. 800 nest-boxes mainly occupied by collared flycatchers.

The collared flycatcher is a small, migratory, insectivorous, primarily monogamous, sexually dichromatic, hole-nesting passerine that breeds in deciduous forests in Europe. Males arrive at the breeding site from the middle of April and immediately start to occupy and defend nest-boxes and their surroundings, while females arrive a bit later and start to search for a mate (Cramp and Perrins 1993). Females lay one clutch per breeding season (except replacement clutches after predation) containing usually 5-7 eggs (range 3-9) that hatch roughly 12 days after clutch completion. The nestling period lasts for 14-16 days. The female incubates the eggs alone, while being fed by its partner (Kötél et al. 2016), and both parents provision the nestlings.

\section{Field procedures}

In every year since 2003 (except 2006), during the settlement and courtship period, we have conducted behavioural tests (measuring novelty avoidance, aggression and risk-taking) on established males (Garamszegi et al. 2006). For the current study, the aggression test is relevant, so we focus on this behavioural trait hereafter. The standard test protocol was described in Garamszegi et al. 2006. From the middle of April (expected arrival time of the first males), we searched our nestbox plots daily for males arriving from their wintering site. Because of the daily schedule of the fieldwork, we assumed that newly found males had arrived just before the given date. Males that were found displaying at a particular nest-box (considered as their natural, chosen nest-site) were subjected to a simulated territorial intrusion test. We put out a live, conspecific decoy male in a small $(15 \times 20 \times 15 \mathrm{~cm})$, clothcovered cage within $2 \mathrm{~m}$ from the focal nest-box. The decoy males were trapped in non-adjacent study plots; therefore, they were most likely unfamiliar to the resident males. In the study period, we used on average 6 (range 3-16) decoy males per year randomly across tests (noting the identity of the decoy at each test). After uncovering the decoy, we immediately retreated to a hiding position in a distance of $30 \mathrm{~m}$ and then assessed the latency of the first attack using binoculars and stopwatch. Latency to attack was defined as the time (measured in seconds) that elapsed between the moments when the resident male detected and first attempted to attack the decoy (specifically, touched its cage from any side). We recorded detection when the resident male reappeared on its territory. We recorded the first attack when the resident male touched the cage for more than $1 \mathrm{~s}$ and showed clear signs of intention to fight (such as ruffling plumage, flicking wings, jumping and pecking). In the first 2 years of the study (2003, 2004), we also assessed the number and the duration of the attacks during the tests. Attack latency proved to be predictive of these other two variables describing aggression (Garamszegi et al. 2006); therefore, because of ethical and logistic reasons, in the consecutive study years, we focused on latency to attack. Attack latency was found to be consistent (i.e. repeatable) within males during a breeding season, and thereby 
qualified as an individual-specific trait (Garamszegi et al. 2006). Note that the latency to attack is an inverse measure of aggression as males that take longer time to attack are considered to be less aggressive and males that attack shortly are considered to be more aggressive. Resident males that did not attack the decoy during the test were given a score of $301 \mathrm{~s}$ as $5 \mathrm{~min}$ is the maximum length of our test. Five minutes was chosen because we intended to restrict the length of our protocol to the necessary minimum and in the first 2 study years; we found that males that did not respond to the decoy in terms of attack within 5 min usually did not attack at all (Garamszegi et al. 2006). When instead of attack latency, we used attack as a binary variable or when we excluded the males that did not attack ( $n=30$ males); our results remained qualitatively the same. Therefore, we kept non-attacker males with $301 \mathrm{~s}$ in the statistical analyses, to rely on the higher resolution of the variable (as compared to a binary variable) and the larger sample size. All tests were done between 6:00 a.m. and 2:00 p.m.

After the standard behavioural tests, we caught the resident males in their nest-box with spring trap for subsequent ringing and measurement procedures. For the current study, the following measurements were used. We measured the tarsus length with a calliper to the nearest $0.1 \mathrm{~mm}$ and the body mass with Pesola spring balance to the nearest $0.1 \mathrm{~g}$. We also measured the size of two white ornaments, the forehead and wing patches, which seem to be sexually selected traits (Michl et al. 2002; Török et al. 2003; Garamszegi et al. 2006; Hegyi et al. 2010) and are related to certain aspects of individual quality (Török et al. 2003; Garamszegi et al. 2004). To estimate wing patch size (WPS), we measured the length of white bars on the 4th-8th primaries with a calliper to the nearest $0.1 \mathrm{~mm}$ (Török et al. 2003). We quantified WPS as the sum of the measured white segments. To estimate the forehead patch size (FPS), we measured the maximum height and length of the patch with a calliper to the nearest $0.1 \mathrm{~mm}$ (Michl et al. 2002; Hegyi et al. 2002). We quantified FPS as the product of these measurements. We also assessed the age of the males based on the colour of their remiges (subadults: brown, adults: black; Svensson 1992). Once the measurements were taken, we marked the males on their abdomen individually with permanent ink markings assigned in a random and factorial design for resighting and released them. With these colour markings, we could ensure that multiple aggression data from the same male from the same year were not used in the statistical analyses. The colour markings wear off in ca. 1 month.

In every year, we monitored the pairing and breeding performances of the birds to gain data about their reproductive success by systematic nest-box checking. We collected the following data for all breeding events in our study plots: calendar date of the first egg, clutch size, hatching success and fledging success. In some cases, the latter two could be influenced by experiments or predation. As we attempt to ring all young before fledging and to catch all breeding birds, from our long-term database, we can estimate the return rate of parents in the next year and the recruitment success of the broods (i.e. the proportion of fledglings that have been recaptured as adults).

\section{Statistical analyses}

We conducted 352 aggression assays in 2003-2016. In the statistical analyses, when a male was tested more than once within the same year, we always considered its first observation in the given year. When a male was tested in more than 1 year, we selected the observation with complete information on other variables or randomly chose one of the complete observations, if more than one complete observation was available. Males that had already established pair-bond during the time of the assay were excluded. We had to disregard the study year of 2008 because only 5 males were assayed successfully in that year, from which 2 males already had a female at the time of the assay and 2 males had entry from another year. After these data selections, the sample size for the statistical analyses was 295 individual males (the minimum and maximum number of individual males tested per year were 6 and 38 , respectively).

To assess the fitness consequences of aggression, we analysed the reproductive performance in the year of the behavioural assay, and the probability of recapture in the following year (used as a proxy for survival) of the tested males. Accordingly, we built statistical models for six different response variables reflecting different determinants and aspects of fitness. (1) Pairing probability was tested as a binary response variable and reflected whether the focal male had been found in social pair-bond or not after the behavioural test. The sample included all tested males $(n=295)$. (2) Pairing speed was tested as a continuous response variable given as the time (in days) elapsed between the date of the behavioural test (which approximates arrival date from the wintering site to the breeding site) and the date of the first egg laid by the social mate. The corresponding sample included those tested males that initiated a clutch $(n=136)$. (3) The probability of predation was again a binary response variable coding whether the clutch or brood had been predated (partially or totally) or not ( $n=136$ males). (4) The number of fledglings was a continuous response variable, for which we used males that had not been a subject to any experiment or predation $(n=101)$. (5) The probability of having at least one recruit was a binary response variable as males typically ended up with a single recruit if any (only 4 males had 2 and one male each had 3 and 4 recruits). This analysis was run for the same sample as the former one except that males tested in the last 2 years of the study $(2015,2016)$ were disregarded as recruitment success could not be assessed for them yet $(n=64$; offspring come back to our study site as 1 and 2 years old with a similar 
probability; our unpublished data, see also Herényi et al. 2012). (6) Return in the next year as a binary response variable was used as a proxy for survival. This analysis was run for all males except those that were tested in the last study year (2016) as this response variable could not be assessed for them yet $(n=260)$.

In all statistical models, the focal explanatory variable was aggression. The raw attack latencies were $\log _{10}(x+1)$ transformed to achieve symmetric distribution. Then, the log-transformed attack latencies were standardised across age categories because subadult males are generally more aggressive during territorial challenge than adult ones (Garamszegi et al. 2006). We included additional control variables as predictors in the models, which were the following: year (continuous variable), date of the test (relative to the median test date of the given year; continuous variable), date of the first egg (relative to the median laying date of the given year; continuous variable), age of the male (subadult or adult; binary variable), FPS, WPS, tarsus length and body condition (continuous variables). In the case of return in the next year, we also included breeding (whether the male bred or not in the year of the behavioural test; binary variable) as a control variable. Test date was standardised across age categories because adult males arrive at the breeding site earlier than subadult ones (our unpublished data). FPS and WPS were also standardised across age categories year by year. Body condition was the residual from linear regression of the body mass on the tarsus length for each year separately. The interaction effect of aggression and age was also considered because of the distinct behaviour of subadult males from adult males during territorial confrontations (Garamszegi et al. 2006). Two-way interactions of control variables and age were also checked using log-likelihood ratio tests (LRT) between models containing and lacking the respective age interaction. Because all $p$ s were $>0.05$, these interactions were not considered in further analyses. Models with the random factor of decoy identity were compared with the models without random factor in case of each response variable, and the simpler models always performed better (LRT; all $p>0.05$ ) so we did not use random factor.

All analyses were run in R statistical environment (version 3.1.1.; R Core Team 2014). We built general linear models (GLM) using the "lm" function (with Gaussian error) for continuous and the "glm" function (with binomial error) for binary response variables ("Ime4" package; Bates et al. 2015). The models were compared based on the Akaike information criterion (AIC) values. The supported sets of models were those within a $\triangle \mathrm{AIC} \leq 2$ (Burnham and Anderson 2004). We present the supported model sets for all the six response variables in an online supplementary material. The significance of the explanatory variables was assessed by their averaged coefficients (with confidence intervals) and relative importance (scale of
0-1) across the supported models ("MuMIn" package; Barton 2016). The distribution of the considered variables and model residuals was verified visually ("boxplot", "dotchart" and "hist" functions). Multicollinearity was not an issue (all VIF < 1.3; Graham 2003, function "vif" of package "car"; Fox and Weisberg 2011).

\section{Results}

The reproductive performance of males did not associate with their level of territorial aggression (Table 1). Timing had a significant role in the case of all but one (the probability of having at least one recruit) estimate of reproductive performance (Table 1). Males that arrive earlier had a higher chance to establish social pair-bond (Table 1, Fig. 1a). In contrast, among successfully paired males, the later the male arrived, the shorter the time interval between arrival date and laying date was (Table 1, Fig. 1b). Arrival date (indicated by the date of the behavioural test) strongly and positively correlated with laying date ( $r=0.377, p<0.001, n=136$ ), and males fledged more offspring if they started to breed earlier (Table 1, Fig. 1c). Older males also had a higher chance to find a social mate, but this did not translate to further advantages in terms of pairing speed, number of fledglings and the probability of having a recruit (Table 1 ). The probability of predation increased during the study years, but it was independent of aggression and all the remaining control variables (Table 1).

The return rate of males was not associated with their aggression per se; however, it was significantly associated with the interaction between age and aggression indicating that the relationship between aggression and return in the next year was dependent on the age of the male (Table 1). Post hoc tests for the separate age categories revealed that among adults, the less aggressive males had a significantly higher chance to be recaptured in the next year $(F=5.558, p=0.020$, estimate $=$ $0.466, \mathrm{SD}=0.200, n=158$; Fig. 2 ). While among subadults, the more aggressive males returned better, although the pattern was statistically less significant $(F=5.558, p=0.020$, estimate $=0.466, \mathrm{SD}=0.200, n=158 ;$ Fig. 2$)$. None of the control variables did relate to the probability of return (Table 1).

\section{Discussion}

In male collared flycatchers, we examined the potential relationship between nest-site defence aggression, pairing success and reproductive output, as well as probability of recapture in the next year (an estimate of survival). We found that aggression was unrelated to pairing success and reproductive output. However, aggression of males was significantly related to their return in the next year, and the direction of the relationship was dependent on the age of the males. Specifically, among 


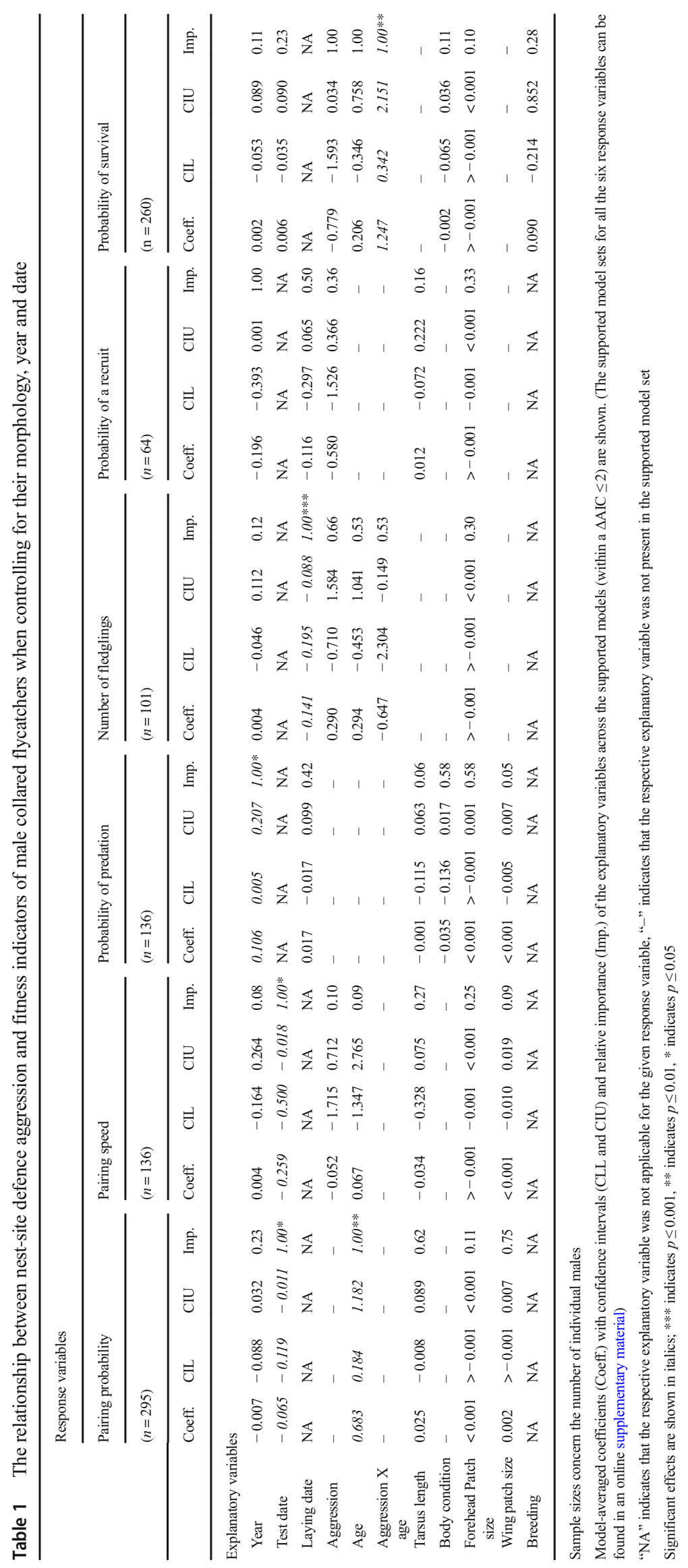




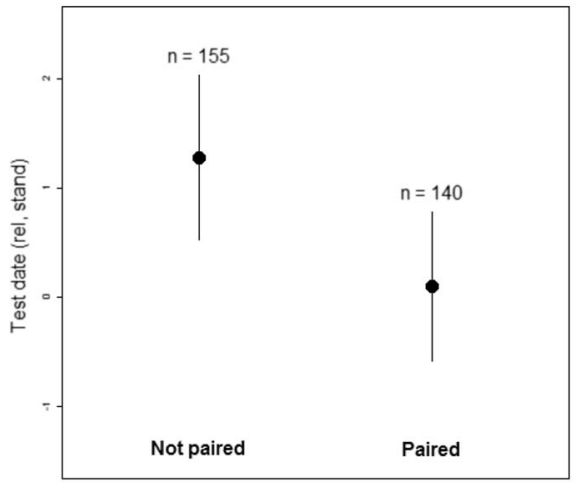

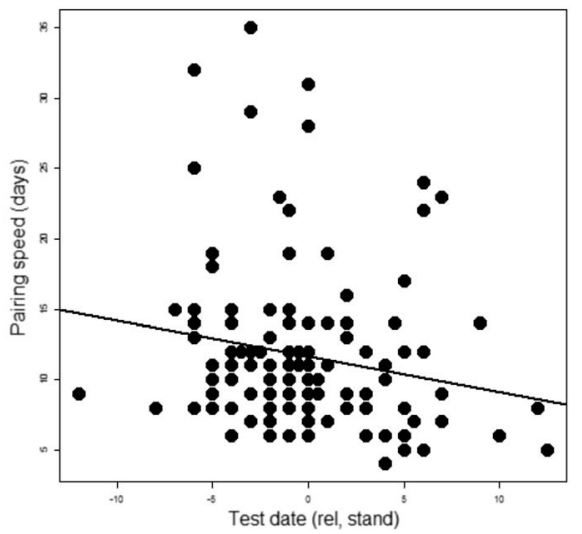

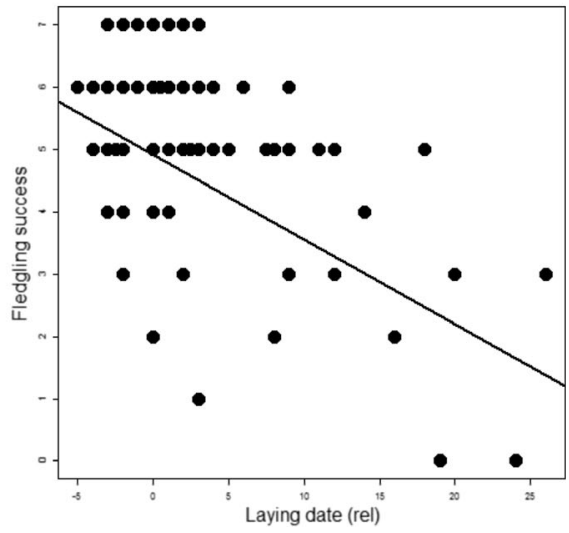

Fig. 1 The relationship between timing and fitness indicators of male collared flycatchers: pairing probability (a) and pairing speed (b) in relation to the date of the simulated territorial intrusion test (which approximates the arrival date from the wintering site to the breeding site) and the number (c) of fledglings in relation to the laying date of the first egg in the clutch. Test date and laying date were calculated relative to the yearly median date. In panel (a), means and $95 \%$ confidence intervals are shown subadult males lacking former breeding experience, more aggressive males returned with a higher probability, while among adult, experienced males, the return pattern was the reverse.

Our results suggest that the fitness pay-off of aggression was dependent on age in our study population of collared flycatchers, and this could be driven by multiple, nonexclusive pressures. The causality, however, is hard to uncover given the correlative nature of our study. It is possible that successful resource acquisition and maintenance require higher aggression from subadult than from adult males, because of their less spatial and social knowledge and thereby more aggressive subadult males may have a higher chance to

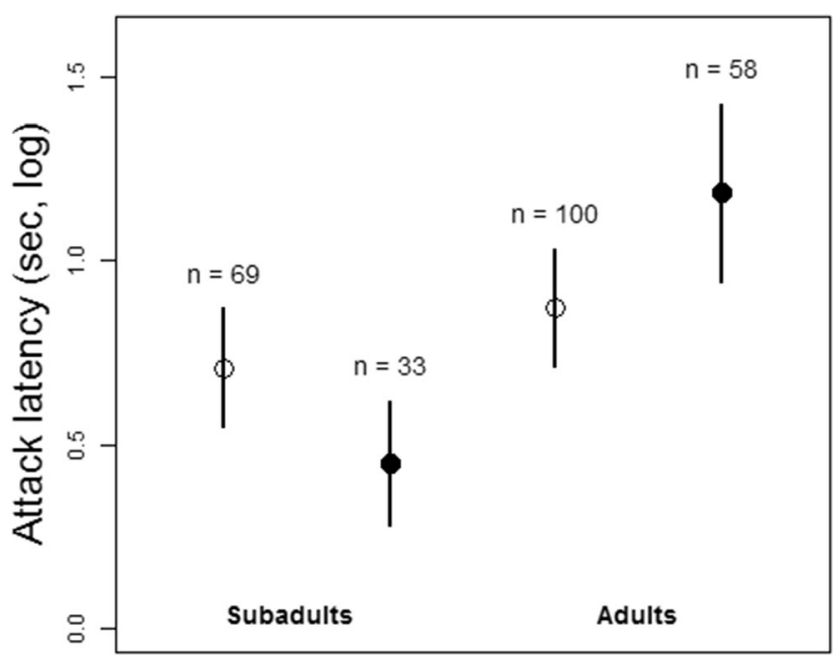

Fig. 2 Return of subadult and adult male collared flycatchers in the next year according to the level of their aggression performed during simulated territorial intrusion in the courtship period. Open circles and filled circles represent not returned and returned males, respectively. Attack latency was measured in seconds, and raw values were $\log _{10}(x+1)$-transformed. (Note that in the statistical analyses, log-transformed attack latencies were age-standardised. Here, we show the unstandardised values for the sake of representativity.) Means and 95\% confidence intervals are shown reach adulthood than less aggressive subadults. At the same time, it is also possible that those subadult males act more aggressively that already have a higher expectation of life, for example, due to inherent effects of individual quality. The detected pattern could also be caused by non-random dispersal, if subadults expressing less aggression fail in nestsite competition, and due to physical exclusion or bad experiences, do not return to the breeding site in subsequent years. We suggest that this scenario is not likely for several reasons. Collared flycatchers are highly philopatric, and their breeding dispersal is low, especially in males (Pärt and Gustafsson 1989; Könczey et al. 1992). Second, less aggressive subadult males were as likely to be paired as more aggressive subadults; therefore, they should not necessarily had strong incentives to disperse farther in the hope of higher reproductive success. Third, in western bluebirds, it has been revealed that aggressive males disperse further (Aguillon and Duckworth 2015). In our study population of collared flycatchers, aggression and risk-taking positively correlate with each other (Garamszegi et al. 2015); therefore, it is reasonable to assume a similar positive relationship between aggression and dispersal tendency, if any. In such a case, breeding experiences and behavioural attitudes of males may counteract, and thereby difference in the dispersal distances of more aggressive and less aggressive subadult males may not manifest.

Regarding the reverse pattern found for adult males, the causality is also uncertain and we can propose multiple explanations. It has been established in the sister species of our study species, the pied flycatcher (Ficedula hypoleuca), that aggressive response to territorial intrusion during the courtship period is accompanied with elevated plasma testosterone level (Silverin 1993). Therefore, one plausible scenario is that the cost of expressing a high level of aggression increases with age because the immunosuppressive effect of testosterone becomes augmented with immunosenescence, and 
consequently, adult males may survive better if they express a less aggressive attitude, and thereby reduce their costs. This scenario is supported by results in male red-legged partridges (Alectoris rufa), namely testosterone-implanted younger males increased their antioxidant capacity, while testosterone-implanted older males were not able to do so, and their cell-mediated immunity was compromised (Alonso-Alvarez et al. 2009). An alternative scenario could be that adult males that already have a higher probability to survive until the next year may refrain from escalating aggressive confrontations. Scenarios for subadult and adult males that are based on the protection of residual reproductive value seem to be in conflict at first, but selective forces may change direction with age. Subadult males breeding for the first time may have to gain experience for their whole lifetime; thus, better future prospects could be coupled with a higher level of aggression. In contrast, adult males that already have experience in the population could save time and energy from engaging in escalating disputes; thus, better future prospects could be coupled with a lower level of aggression.

Our current finding is in agreement with our earlier results that subadult males generally behave bolder than adult males, which is not only true for territorial disputes (i.e. shorter attack latencies; Garamszegi et al. 2006) but also for risk-taking (i.e. shorter flight initiation distances; Jablonszky et al. 2017). The reverse effect of aggression on survival to next year in subadults and adults could explain why we found a difference in aggression between the age categories. In a wild, nest-box breeding population of blue tits (Cyanistes caeruleus), aggressive response to handling has also been found to decrease with age (Class and Brommer 2016). However, survival of blue tits was independent of their aggression during handling, and aggressive males reared more recruited offspring, especially when their breeding partner was also aggressive (Class et al. 2014). Age interactions on fitness, however, were not considered in the blue tit (Class et al. 2014), and the difference in aggression was attributed to ageing itself (Class and Brommer 2016). Study on a bighorn sheep (Ovis canadensis) population found that docility, an inverse of aggression, had a positive effect on lifespan independent of age, but it had a negative effect on annual reproductive success in younger males and a positive effect in older males (Réale et al. 2009). Therefore, increasing docility (i.e. decreasing aggression) with advancing age seems to be beneficial for bighorn males. This could be due to age-dependent mating tactics. Older males monopolise and guard their mates, while younger males have to compete and chase away the older males to get access to a receptive female (Réale et al. 2009). Patrick and Weimerskirch (2015) found that wandering albatrosses (Diomedea exulans) change their foraging style as they age according to their boldness, and in males, this was associated with a higher probability to fledge offspring (their survival was not analysed). Then, it is possible that in the background of the different aggression-related survival of subadult and adult collared flycatcher males, there is a change in foraging or migrating strategy with age. According to several studies including ours, the relationship between residual asset and the expression of boldness-like or risky behaviours is not overwhelmingly evident and could depend on the life-history of the species. For example, blue tits and collared flycatchers are short-lived birds with large clutch sizes (fast life-history), while the wandering albatross is one of the longest-lived birds and lays only one egg in every other year (slow lifehistory), and such differences could alter the optimal relationship between residual asset and the magnitude of boldness or risk-taking at the individual level. Clearly, future studies on different species are needed to explore and generalise how boldness-like or risky behaviours change with age, and whether these changes are adaptive or consequences of systematic senescence.

We did not find any effect of aggression on pairing and reproductive success of males. In an earlier study based on 3 study years (2003-2005), aggression was related to pairing speed (Garamszegi et al. 2006). Here, we failed to confirm this relationship. As attack latencies did not differ between years of the present study $\left(\operatorname{GLM}: F_{(1,293)}=\right.$ $0.064, p=0.800, n=295$ ), and the interactive effect of attack latency and year was non-significant on pairing speed $\left(\mathrm{GLM}: F_{(1,132)}=0.048, p=0.827, n=136\right)$, yearspecific effect of aggression on fitness is not a likely an explanation for the inconsistency in results. It may be rather caused by the difference in sample sizes $(n=29$ and 136 males earlier and here, respectively). Recently, in a videotaped subset of the tested males, the nestling feeding activity of more and less aggressive males was found to be similar when controlling for their morphology and the morphology and feeding activity of their breeding partner (Szász et al. manuscript under review). This finding could explain why more and less aggressive males fledged a similar number of offspring and had a similar chance to have at least one recruit. Altogether, our results suggest that reproductive success of more aggressive and less aggressive collared flycatcher males is similar. However, we cannot completely rule out the link between aggression and reproductive success. First, we might underestimate the variation in male reproductive success, because we could not control for extra-pair fertilisations, which occur in our study population (Michl et al. 2002; Rosivall et al. 2009). Second, earlier studies in our population demonstrated that lifetime reproductive success of males is strongly influenced by the number of their breeding events (Herényi et al. 2012; Szász et al. 2017). Accordingly, through its effect on survival to next year, 
aggression could potentially influence the lifetime reproductive success of males, which requires further data and investigation.

The pairing probability of males was predicted by the date they arrived at the breeding site and their age as earlier arriving and older males were more likely to be found as breeders. These patterns had been described in other species too (American redstart (Setophaga ruticilla), Lozano et al. 1996; barn swallow (Hirundo rustica), Møller 1994; eastern kingbird (Tyrannus tyrannus), Cooper et al. 2011). Older males did not differ from males breeding for the first time in other aspects of pairing and reproductive performance. Arrival date also directly influenced the speed of pairing and, through its effect on clutch initiation date, the outcome of current-year reproduction. Among successfully paired males, those that arrived later seemed to pair more quickly than those that arrived earlier. This could be due to the time constraints and the narrowing pool of available females. However, those paired males that arrived earlier also started to breed earlier and thereby fledged more offspring. In seasonally breeding songbirds, it is a wellknown phenomenon that conditions for successful breeding are deteriorating with the progress of the season, and in parallel, the number of fledglings is declining (Verhulst and Nilsson 2008). Furthermore, it is possible that earlier arriving males are of better quality and so are their breeding partners, and these pairs realise higher fledging success also as a consequence of their inherent superiority (Verhulst et al. 1995). The probability of having at least one returning offspring did not relate to any variables that we considered. We could have failed to capture the variation in this aspect of reproductive performance. The majority of males do not produce any recruit during their entire lifetime, and the probability of producing at least one recruit is strongly increasing with increasing lifetime (Herényi et al. 2012). Therefore, correlates of this aspect of reproductive performance could have been detectable only if we had data for the males assayed for territorial aggression throughout their life, but this data is available only for a fraction that is insufficient for statistical analyses.

In conclusion, in a wild population of collared flycatchers, we found correlative evidence that nest-site defence aggression of males during the courtship period is a fitness-related trait as it was associated with survival until the next year. However, the fitness pay-off appears to be dependent on age as the relationship between aggression and survival changed direction between the subadult and the adult age categories. Reproductive output of the males in the respective year was independent of their aggression, but via its effect on survival to the next year, aggression may be related to reproductive success in the long-term. It would be ideal to know the relationship between aggression and fitness in longitudinal data from the individuals. However, these data are hard to obtain in the wild. Even in our 14-year database, we had an entry about behaviour, morphology and reproductive performance over multiple years from only $8 \%$ of the males. Perhaps in a more closed, isolated population, it would be possible to gather such data. Nonetheless, our study highlights the importance of considering age-interactions in studies exploring the fitness correlates of ecologically relevant, individual-specific behaviours because expression of those behaviours and allocation solutions for life-history trade-offs are expected to change with age due to multiple reasons, for example due to reduction in residual asset or senescence.

Acknowledgements Open access funding provided by Eötvös Loránd University (ELTE). We thank the members of the Behavioural Ecology Group for their help in the field. We are thankful to the Erdők a Közjóert Alapítvány and the Pilis Park Forestry for their support.

Funding information The study was supported by the following grants: $\mathrm{PhD}$ scholarship to JM, KK, LM, NG and ESzász from the Doctoral School of Biology, Eötvös Loránd University, Hungary; scholarship to ESzász (grant no. ÚNKP-16-3-ELTE-8495/6/2016) from the New National Excellence Program of the Ministry of Human Capacities, Hungary; scholarship to GM (grant no. 20430-3/2018/FEKUTSTRAT) from the Higher Education Institutional Excellence Program of the Ministry of Human Capacities, Hungary; János Bolyai research scholarship to BR and ESzöllösi from the Hungarian Academy of Sciences; NKFIH research grants to BR (grant no. K120249), GH (grant no. K124443), JT (grant no. K115970), LZG (grant no. K129215), MH (PD121276) and ESzöllősi (PD124043) from the Hungarian National Research, Development and Innovation Office; research grant to LZG (grant no. CGL2015-70639-P) from the Ministry of Economy and Competitiveness, Spain.

\section{Compliance with ethical standards}

The field procedures were evaluated and received prior approval by the Department of Environment and Nature Protection of the Hungarian Government Office and meet the ASAB/ABS guidelines for the use of animals in research. The behavioural assays were carefully designed to minimise the stress for the resident and decoy birds (Garamszegi et al. 2009). All authors are licensed to handle and test animals by the Committee on Animal Welfare of the Eötvös Loránd University.

Open Access This article is distributed under the terms of the Creative Commons Attribution 4.0 International License (http:// creativecommons.org/licenses/by/4.0/), which permits unrestricted use, distribution, and reproduction in any medium, provided you give appropriate credit to the original author(s) and the source, provide a link to the Creative Commons license, and indicate if changes were made.

Publisher's note Springer Nature remains neutral with regard to jurisdictional claims in published maps and institutional affiliations.

\section{References}

Aguillon SM, Duckworth RA (2015) Kin aggression and resource availability influence phenotype-dependent dispersal in a passerine bird. Behav Ecol Sociobiol 69:625-633. https://doi.org/10.1007/s00265015-1873-5 
Alatalo RV, Lundberg A, Ståhlbrandt K (1984) Female mate choice in the pied flycatcher Ficedula hypoleuca. Behav Ecol Sociobiol 14:253261. https://doi.org/10.1007/BF00299496

Alatalo RV, Lundberg A, Glynn C (1986) Female pied flycatchers choose territory quality and not male characteristics. Nature 323:152-153. https://doi.org/10.1038/323152a0

Alonso-Alvarez C, Pérez-Rodríguez L, Garcia JT, Viñuela J (2009) Testosterone-mediated trade-offs in the old age: a new approach to the immunocompetence handicap and carotenoid-based sexual signalling. Proc R Soc Lond B Biol Sci 276:2093-2101. https://doi.org/ $10.1098 / \mathrm{rspb} .2008 .1891$

Bartoń K (2016) MuMIn: multi-model inference. R package version 1.15.6. http://CRAN.R-project.org/package=MuMIn

Bates D, Maechler M, Bolker B, Walker S (2015) Fitting linear mixedeffects models using lme4. J Stat Softw 67:1-48. https://doi.org/10. 18637/jss.v067.i01

Bensch S, Hasselquist D (1991) Territory infidelity in the polygynous great reed warbler Acrocephalus arundinaceus:the effect of variation in territory attractiveness. J Anim Ecol 60:857-871. https://doi. org $/ 10.2307 / 5418$

Berglund A, Bisazza A, Pilastro A (1996) Armaments and ornaments: an evolutionary explanation of traits of dual utility. Biol J Linn Soc 58: 385e399-385e399. https://doi.org/10.1006/bijl.1996.0043

Betini GS, Norris DR (2012) The relationship between personality and plasticity in tree swallow aggression and the consequences for reproductive success. Anim Behav 83:137-143. https://doi.org/10. 1016/j.anbehav.2011.10.018

Burnham KP, Anderson DR (2004) Multimodel inference - understanding AIC and BIC in model selection. Sociol Methods Res 33:261304. https://doi.org/10.1177/0049124104268644

Burtka JL, Grindstaff JL (2013) Repeatable nest defense behavior in a wild population of Eastern bluebirds (Sialia sialis) as evidence of personality. Acta Ethol 16:135-146. https://doi.org/10.1007/ s10211-013-0143-7

Cain KE, Ketterson ED (2012) Competitive females are successful females; phenotype, mechanism and selection in a common songbird. Behav Ecol Sociobiol 66:241-252. https://doi.org/10.1007/s00265011-1272-5

Cain KE, Rich MS, Ainsworth K, Ketterson ED (2011) Two sides of the same coin? Consistency in aggression to conspecifics and predators in a female songbird. Ethology 117:786-795. https://doi.org/10. 1111/j.1439-0310.2011.01932.x

Candolin U (2000) Male-male competition ensures honest signaling of male parental ability in the three-spined stickleback (Gasterosteus aculeatus). Behav Ecol Sociobiol 49:57e61. https://doi.org/10.1007/ s002650000267

Class B, Brommer JE (2016) Senescence of personality in a wild bird. Behav Ecol Sociobiol 70:733-744. https://doi.org/10.1007/s00265016-2096-0

Class B, Kluen E, Brommer JE (2014) Evolutionary quantitative genetics of behavioral responses to handling in a wild passerine. Ecol Evol 4: 427-440. https://doi.org/10.1002/ece3.945

Cooper NW, Murphy MT, Redmond LJ, Dolan AC (2011) Reproductive correlates of spring arrival date in the Eastern kingbird Tyrannus tyrannus. J Ornithol 152:143-152. https://doi.org/10.1007/s10336010-0559-Z

Cramp S, Perrins CM (1993) The birds of the Western Palearctic, VII. Flycatchers to shrikes. Oxford University Press, Oxford

Duckworth RA (2006) Behavioral correlations across breeding contexts provide a mechanism for a cost of aggression. Behav Ecol 17:10111019. https://doi.org/10.1093/beheco/arl035

Dunn J, Cole E, Quinn JL (2011) Personality and parasites: sexdependent associations between avian malaria infection and multiple behavioural traits. Behav Ecol Sociobiol 65:1459-1471. https:// doi.org/10.1007/s00265-011-1156-8
Ens BJ, Kersten M, Brenninkmeijer A, Hulscher JB (1992) Territory quality, parental effort and reproductive success of oystercatchers (Haematopus ostralegus). J Anim Ecol 61:703-715. https://doi. org/10.2307/5625

Folstad I, Karter AK (1992) Parasites, bright males, and the immunocompetence handicap. Am Nat 139:603-622. https://doi.org/10.1086/ 285346

Fox J, Weisberg S (2011) An $\{\mathrm{R}\}$ companion to applied regression, 2nd edn. Sage, Thousand Oaks http://socserv.socsci.mcmaster.ca/jfox/ Books/Companion

Fretwell SD, Calver JS (1970) On territorial behavior and other factors influencing habitat distribution in birds. Acta Biotheor 19:37-44. https://doi.org/10.1007/BF01601955

Garamszegi LZ, Török J, Michl G, Møller AP (2004) Female survival, lifetime reproductive success and mating status in a passerine bird. Oecologia 138:48-56. https://doi.org/10.1007/s00442-003-1408-z

Garamszegi LZ, Rosivall B, Hegyi G, Szöllösi E, Török J, Eens M (2006) Determinants of male territorial behavior in a Hungarian collared flycatcher population: plumage traits of residents and challengers. Behav Ecol Sociobiol 60:663-671. https://doi.org/10.1007/s00265006-0210-4

Garamszegi LZ, Török J, Eens M (2008) Birds reveal their personality when singing. PLoS One 3:e2647. https://doi.org/10.1371/journal. pone. 0002647

Garamszegi LZ, Eens M, Török J (2009) Behavioural syndromes and trappability in free-living collared flycatchers, Ficedula albicollis. Anim Behav 77:803-812. https://doi.org/10.1016/j.anbehav.2008. 12.012

Garamszegi LZ, Rosivall B, Rettenbacher S, Markó G, Zsebők S, Szöllősi E, Eens M, Potti J, Török J (2012) Corticosterone, avoidance of novelty, risk-taking and aggression in a wild bird: no evidence for pleiotropic effects. Ethology 118:621-635. https://doi.org/ 10.1111/j.1439-0310.2012.02049.x

Garamszegi LZ, Markó G, Szász E, Zsebők S, Azcárate M, Herczeg G, Török J (2015) Among-year variation in the repeatability, withinand between-individual, and phenotypic correlations of behaviors in a natural population. Behav Ecol Sociobiol 69:2005-2017. https:// doi.org/10.1007/s00265-015-2012-z

Graham MH (2003) Confronting multicollinearity in ecological multiple regression. Ecology 84:2809-2815. https://doi.org/10.1890/02-3114

Grenna M, Avidano L, Malacarne G, Leboucher G, Cucco M (2014) Influence of male dominance on egg testosterone and antibacterial substances in the egg of grey partridges. Ethology 120:149-158. https://doi.org/10.1111/eth.12189

Harris MR, Siefferman L (2014) Interspecific competition influences fitness benefits assortative mating for territorial aggression in eastern bluebirds (Sialia sialis). PLoS One 9:e88668. https://doi.org/10. 1371/journal.pone.0088668

Hegyi G, Török J, Tóth L (2002) Qualitative population divergence in proximate determination of a sexually selected trait in the collared flycatcher. J Evol Biol 15:710-719. https://doi.org/10.1046/j.14209101.2002.00449.x

Hegyi G, Szöllősi E, Jenni-Eiermann S, Török J, Eens M, Garamszegi LZ (2010) Nutritional correlates and mate acquisition role of multiple sexual traits in male collared flycatchers. Naturwissenschaften 97 : 567-576. https://doi.org/10.1007/s00114-010-0672-0

Herényi M, Hegyi G, Garamszegi LZ, Hargitai R, Michl G, Rosivall B, Török J (2012) Lifetime offspring production in relation to breeding lifespan, attractiveness, and mating status in male collared flycatchers. Oecologia 170:935-942. https://doi.org/10.1007/s00442-012-2362-4

Hof D, Hazlet N (2012) Mortal combat: an apparent intraspecific killing by a male black-capped chickadee. J Field Ornithol 83:290-294. https://doi.org/10.1111/j.1557-9263.2012.00377.x

Jablonszky M, Szász E, Markó G, Török J, Herczeg G, Garamszegi LZ (2017) Escape ability and risk-taking behaviour in a Hungarian 
population of the collared flycatcher (Ficedula albicollis). Behav Ecol Sociobiol 71:54. https://doi.org/10.1007/s00265-017-2276-6

Könczey R, Török J, Tóth L (1992) Költéssiker és költési területhűség az örvös légykapónál (Ficedula albicollis). Állat Közl 78:69-77

Kötél D, Laczi M, Török J, Hegyi G (2016) Mutual ornamentation and the parental behaviour of male and female collared flycatchers Ficedula albicollis during incubation. Ibis 158:796-807. https:// doi.org/10.1111/ibi.12389

Kunc HP, Amrhein V, Naguib M (2006) Vocal interactions in nightingales, Luscinia megarhynchos: more aggressive males have higher pairing success. Anim Behav 72:25-30. https://doi.org/10.1016/j. anbehav.2005.08.014

Lozano GA, Perreault S, Lemon RE (1996) Age, arrival date and reproductive success of male American redstarts Setophaga ruticilla. J Avian Biol 27:164-170. https://doi.org/10.2307/3677146

Maynard Smith J, Harper DGC, Brookfield JFY (1988) The evolution of aggression: can selection generate variability? Philos Trans R Soc Lond Ser B Biol Sci 319:557-570. https://doi.org/10.1098/rstb.1988.0065

Michl G, Török J, Griffith S, Sheldon BC (2002) Experimental analysis of sperm competition mechanisms in a wild bird population. Proc Natl Acad Sci U S A 99:5466-5470. https://doi.org/10.1073/pnas. 082036699

Møller AP (1994) Phenotype-dependent arrival time and its consequences in a migratory bird. Behav Ecol Sociobiol 35:115-122. https://doi.org/10.1007/BF00171501

Mutzel A, Dingemanse NJ, Araya-Ajoy YG, Kempenaers B (2013) Parental provisioning behaviour plays a key role in linking personality with reproductive success. Proc R Soc Lond B Biol Sci 280: 10-19. https://doi.org/10.1098/rspb.2013.1019

Ophir AG, Galef BG Jr (2003) Female Japanese quail that 'eavesdrop' on fighting males prefer losers to winners. Anim Behav 66:399-407. https://doi.org/10.1006/anbe.2003.2230

Ophir AG, Persaud KN, Galef BG Jr (2005) Avoidance of relatively aggressive male Japanese quail (Coturnix japonica) by sexually experienced conspecific females. J Comp Psychol 119(1):3-7. https:// doi.org/10.1037/0735-7036.119.1.3

Otter K, McGregor PK, Terry AMR, Burford FRL, Peake TM, Dabelsteen T (1999) Do female great tits (Parus major) assess males by eavesdropping? A field study using interactive song playback. Proc R Soc Lond B Biol Sci 266:1305-1309. https://doi.org/10. 1098/rspb.1999.0779

Pärt T, Gustafsson L (1989) Breeding dispersal in the collared flycatcher (Ficedula albicollis): possible causes and reproductive consequences. J Anim Ecol 58:305-320. https://doi.org/10.2307/5002

Patrick S, Weimerskirch H (2015) Senescence rates and late adulthood reproductive success are strongly influenced by personality in a long-lived seabird. Proc R Soc Lond B Biol Sci 282:20141649. https://doi.org/10.1098/rspb.2014.1649

R Core Team (2014) R: a language and environment for statistical computing. R Foundation for Statistical Computing, Vienna http://www. R-project.org/

Réale D, Martin J, Coltman DW, Poissant J, Festa-Bianchet M (2009) Male personality, life-history strategies and reproductive success in a promiscuous mammal. J Evol Biol 22:1599-1607. https://doi.org/ 10.1111/j.1420-9101.2009.01781.x

Réale D, Garant D, Humphries MM, Bergeron P, Careau V, Montiglio PO (2010) Personality and the emergence of the pace-of-life syndrome concept at the population level. Philos Trans R Soc Lond Ser B Biol Sci 365:4051-4063. https://doi.org/10.1098/rstb.2010.0208

Robinson SK, Terborgh J (1995) Interspecific aggression and habitat selection by Amazonian birds. J Anim Ecol 64:1-11. https://doi. org $/ 10.2307 / 5822$

Rojas Mora A, Meniri M, Ciprietti S, Helfenstein F (2017) Social dominance explains within-ejaculate variation in sperm design in a passerine bird. BMC Evol Biol 2017:66. https://doi.org/10.1186/ s12862-017-0914-2
Rosivall B, Szöllősi E, Hasselquist D, Török J (2009) Effects of extra-pair paternity and sex on nestling growth and condition in the collared flycatcher, Ficedula albicollis. Anim Behav 77:611-617. https://doi. org/10.1016/j.anbehav.2008.11.009

Rosvall KA (2008) Sexual selection on aggressiveness in females: evidence from an experimental test with tree swallows. Anim Behav 75:1603-1610. https://doi.org/10.1016/S0003-3472(88)80158-1

Rosvall KA (2011) Cost of female intrasexual aggression in terms of offspring quality: a cross-fostering study. Ethology 117:1-13. https://doi.org/10.1111/j.1439-0310.2011.01881.x

Scales J, Hyman J, Hughes M (2013) Fortune favours the aggressive: territory quality and behavioural syndromes in song sparrows, Melospiza melodia. Anim Behav 85:441-451. https://doi.org/10. 1016/j.anbehav.2012.12.004

Sheldon BC, Verhulst S (1996) Ecological immunology: costly parasite defences and trade-offs in evolutionary ecology. Trends Ecol Evol 11:317-321. https://doi.org/10.1016/0169-5347(96)10039-2

Sih A, Bell A, Johnson JC (2004) Behavioral syndromes: an ecological and evolutionary overview. Trends Ecol Evol 19:372-378. https:// doi.org/10.1016/j.tree.2004.04.009

Silverin B (1993) Territorial aggressiveness and its relation to the endocrine system in the pied flycatcher. Gen Comp Endocrinol 89:206213. https://doi.org/10.1006/gcen.1993.1025

Spoon TR, Millam JR, Owings DH (2007) Behavioural compatibility, extrapair copulation and mate switching in a socially monogamous parrot. Anim Behav 73:815-824. https://doi.org/10.1016/j.anbehav. 2006.10.010

Svensson L (1992) Identification guide to European passerines. British Trust for Ornithology, Stockholm

Szász E, Garamszegi LZ, Hegyi G, Szöllősi E, Markó G, Török J, Rosivall B (2014) Aggressive behavior of the male parent predicts brood sex ratio in a songbird. Naturwissenschaften 101:653-660. https://doi.org/10.1007/s00114-014-1204-0

Szász E, Szöllősi E, Hegyi G, Török J, Rosivall B (2017) Rearing conditions have long-term sex-specific fitness consequences in the collared flycatcher. Behav Ecol 28:717-723. https://doi.org/10.1093/ beheco/arx018

Szymkowiak J, Kuczyński L (2017) Song rate as a signal of male aggressiveness during territorial contests in the wood warbler. J Avian Biol 48:275-283. https://doi.org/10.1111/jav.00969

Török J, Hegyi G, Garamszegi LZ (2003) Depigmented wing patch size is a condition-dependent indicator of viability in male collared flycatchers. Behav Ecol 14:382-388. https://doi.org/10.1093/beheco/14.3.382

van Noordwijk AJ, de Jong G (1986) Acquisition and allocation of resources: their influence on variation in life history tactics. Am Nat 128:137-142. https://doi.org/10.1086/284547

van Oers K, Drent PJ, Dingemanse NJ, Kempenaers B (2008) Personality is associated with extrapair paternity in great tits, Parus major. Anim Behav 76:555-563. https://doi.org/10.1016/j.anbehav.2008.03.011

Verbeek EM, Boon A, Drent PJ (1996) Exploration, aggressive behaviour and dominance in pair-wise confrontations of subadult male great tits. Behaviour 133:945-963. https://doi.org/10.1163/156853996X00314

Verhulst S, Nilsson JA (2008) The timing of birds' breeding seasons: a review of experiments that manipulated timing of breeding. Philos Trans R Soc Lond Ser B Biol Sci 363:399-410. https://doi.org/10. 1098/rstb.2007.2146

Verhulst S, van Balen JH, Tinbergen JM (1995) Seasonal decline in reproductive success of the great tit: variation in time or quality? Ecology 76:2392-2403. https://doi.org/10.2307/2265815

Williams GC (1966) Natural selection, the costs of reproduction, and a refinement of Lack's principle. Am Nat 100:687-692. https://doi. org/10.1086/282461

Yasukawa K (1979) Territory establishment in red-winged blackbirds: importance of aggressive behavior and experience. Condor 81: 258-264. https://doi.org/10.2307/1367628 